\title{
Assessment of Reproductive and Sexual Health Literacy of Women in Armenia
}

\section{Mariam Barseghyan, $M D, M S^{1,2^{*}}$, Hayk Barseghyan, $P h D^{3,4}$, Gardenia E Nahigian, $B A^{5}$, Eric J Vilain, MD, PhD ${ }^{3,4}$, Elena Sagayan, MD, MPH ${ }^{2,6}$ and Michael S Wilkes, MD, MPH, PhD}

${ }^{1}$ School of Medicine, University of California Davis, USA

${ }^{2}$ Armenian Health Care Association of the Bay Area, USA

${ }^{3}$ Children's National Health System, Children's Research Institute, USA

${ }^{4}$ Department for Genomics and Precision Medicine, George Washington University, USA

${ }^{5}$ Center for Genetic Medicine Research, University of California Davis, USA

${ }^{6}$ Department of Women's Health, Kaiser Permanente, USA

*Corresponding author: Mariam Barseghyan, MD, MS, University of California Davis School of Medicine, Sacramento, CA, USA; Armenian Health Care Association of the Bay Area, Mountain View, CA, USA

\begin{abstract}
Background: In Armenia, women's health and reproductive choices are limited. According to the World Health Organization (WHO), the incidence of cervical cancer in Armenia has risen from 11 to 14 per 100,000 women in the last 15 years [1]. The WHO also reports that poor knowledge about HIV prevention contributes to low rates of condom use and thus year-to-year increasing rates of HIV particularly among migrant male populations, people who inject drugs, men who have sex with men and sex workers in Armenia [2]. Our study sought to obtain data exploring knowledge of Armenian women around issues related to women's health, specifically sexually transmitted infections (STIs) and cervical cancer while also assessing their contraceptive choices.

Methods: Study consisted of 173 female participants (medical personnel and general respondents) from villages of Armavir and Lori Marz in the Northern Armenia who completed confidential self-filled and validated surveys in Armenian. Questions covered demographics and addressed risk factors, symptoms, and modes of prevention of STIs and cervical cancer as well as contraceptive choices of women. Respondents' answers were tabulated, and common themes identified. Comparison was made between general population and health care workers level of knowledge on specific topic.
\end{abstract}

Results: Both general population and medical personnel demonstrated lack of knowledge of diseases classified as STIs, with only $13 \%$ and $41 \%$ of respondents being able to correctly identify a disease as an STI entity respectively. Overall knowledge of human papilloma virus (HPV) as a cause of cervical cancer was low among both groups, with only $7 \%$ of general population and $31 \%$ health professionals being able to link HPV to the risk of developing cervical cancer. Most participants correctly identified PAP smear as a method of cervical cancer prevention; however, only $11 \%$ of general population and none of the surveyed health care workers believed that HPV vaccination can prevent cervical cancer. Most respondents (88\%) used no mode of contraception. Among those who used contraception, condoms were the most common method $(22 \%)$ with $5 \%$ of respondents using oral combination pills. Nearly third of all respondents marked having had at least one abortion.

Conclusion: In this study, we identified a significant deficit of knowledge regarding reproductive health, specifically, STIs and cervical cancer modes of prevention and methods of effective contraception. Furthermore, the poor knowledge of these subjects was shared by medical professionals. Improvements in the area of health education are needed to promote safe sexual practices proven to decrease the risk of STI exposure, support HPV vaccination campaign and use of modern methods of contraception.

\section{Keywords}

Armenia, Cervical cancer, Sexually Transmitted Infections (STIs), Contraception, Reproductive and sexual health literacy

Citation: Barseghyan M, Barseghyan H, Nahigian GE, Vilain EJ, Sagayan E, et al. (2019) Assessment of Reproductive and Sexual Health Literacy of Women in Armenia. Int J Womens Health Wellness 5:107. doi.org/10.23937/2474-1353/1510107

Accepted: November 05, 2019: Published: November 07, 2019

Copyright: (C) 2019 Barseghyan M, et al. This is an open-access article distributed under the terms of the Creative Commons Attribution License, which permits unrestricted use, distribution, and reproduction in any medium, provided the original author and source are credited. 


\section{Abbreviations}

STIs: Sexually Transmitted Infections; HPV: Human PapilIoma Virus; IUD: Intrauterine Device; PID: Pelvic Inflammatory Disease

\section{Introduction}

In a modern-day Armenia, topics concerning reproductive health, sex and sexuality are still only whispered about. Women's health and reproductive choices in Armenia reflect lack of reproductive and sexual education in the country and poor access to a full range of reproductive services. According to the Article 5 of the Armenian Law on Reproductive Health and Rights to Reproduction, adolescents have right to sexual and reproductive health education provided by professionals in public schools and other educational institutions and organized and implemented by executive bodies in education and healthcare services. Adolescents also have a right to receive confidential and easily available medical consultation and assistance for their reproductive and sexual wellbeing [3]. Part of reproductive and sexual health education is covered in a such courses as biology and classes called "Healthy Lifestyle" and "Safe Activities" as part of the "Preliminary Military Preparedness" course [4]. However, despite the law, there is no structured and regulated educational program that covers the necessary topics related to reproductive and sexual health. In part this is due to cultural taboos surrounding these topics, lack of educational resources, as well as an absence of qualified teachers or health professionals who are knowledgeable about these topics [5]. Thus, most people are left without reliable source of information about reproductive health.

Despite improved access to care and implementation of universal screening for cervical cancer, rates for such diseases as sexually transmitted infections (STIs) and cervical cancer in Armenia remain high. According to the World Health Organization (WHO), the incidence of cervical cancer in Armenia has risen from 11 to 14 per 100,000 women in the last 15 years [1]. Moreover, there has been a sharp increase in the number of diagnosed cases that remain untreated contributing to cervical cancer mortality. Low socioeconomic status amongst the majority of the population, male seasonal labor migration, and lack of understanding of STIs and cervical cancer risk factors, symptoms, and modes of prevention are some of the factors attributed to amplified occurrence of these illnesses in Armenia. According to the WHO poor knowledge about HIV prevention contributes to low rates of condom use and thus year-toyear increasing rates of HIV particularly among migrant male populations, people who inject drugs, men who have sex with men and sex workers in Armenia. Though Armenia has a low HIV presence overall, an estimated 4,000 people in Armenia are currently living with HIV and only a small fraction receives treatment or preventative therapy [2]. Research shows that STIs have been disproportionally affecting young adults and that measures taken to focus on educating youth about the means of STI prevention have been effective in reducing infection rates [6].

Steps toward improving the knowledge about STIs and cervical cancer, as well as measures of their prevention, have been undertaken in Armenia over the recent years which included addition of sexual health education in the public-school curriculum as is discussed above. In addition, multiple nongovernmental organizations (NGOs) and community organizations have sought to develop sexual health educational resources and facilitate health screenings for STIs, cervical cancer, and HIV for patients in cities and rural areas. Nevertheless, given continuous increase in the incidence of STIs and cervical cancer despite measures taken, deeper examination of the problem was deemed to be necessary with a particular concentration on rural communities since these regions are frequently omitted from similar studies. Hence, our study sought to obtain data exploring the extent of knowledge of Armenian women as well as health care representatives in areas related to reproductive and sexual health.

\section{Methods}

This community based cross-sectional study sought to evaluate the state of knowledge of predominantly rural Armenian women regarding risk factors, symptoms, and modes of prevention of STIs and cervical cancer. Contraceptive choices of women were also assessed. Survey questions addressing these topics and basic demographic information were designed by Armenian experts in women's health. All survey questions were translated into Armenian using common language and avoiding medical jargon (Supplementary Material 1 and Supplementary Material 2). The survey was pilot tested among the local Armenian team of collaborators.

Surveys were distributed in three select communities with the help of healthcare department of the Children of Armenia Fund (COAF), a non-profit, non-governmental organization whose goal is to advance rural communities by improving education, healthcare, economic development and village life. Partnered with COAF, our team visited village clinics where we, alongside the COAF medical team, preformed well-woman exams while also distributing surveys to women in the waiting rooms. Surveys were distributed in Armenian by research team representatives. Participants were given unlimited time to complete surveys independently and without consulting books or technology. Prior to handing out the surveys, verbal consent was obtained after assuring participants that responses would be anonymous. Questionnaires were also completed by village medical staff. Surveys were distributed in Yerevan and 
Table 1: Demographic data of the survey participants.

\begin{tabular}{|c|c|}
\hline Category & $\begin{array}{l}\text { Response Frequency } N=173 \\
{[x \%(n=y)]}\end{array}$ \\
\hline \multicolumn{2}{|l|}{ 1. Age } \\
\hline $15-24$ & $9 \%(n=16)$ \\
\hline $25-34$ & $35 \%(n=61)$ \\
\hline $35-44$ & $23 \%(n=40)$ \\
\hline $45-54$ & $12 \%(n=21)$ \\
\hline $55-64$ & $13 \%(n=22)$ \\
\hline $65-74$ & $1 \%(n=1)$ \\
\hline $75-85$ & $1 \%(n=2)$ \\
\hline No response & $6 \%(n=10)$ \\
\hline \multicolumn{2}{|l|}{ 2. Education } \\
\hline High School & $48 \%(n=83)$ \\
\hline College & $27 \%(n=47)$ \\
\hline University & $24 \%(n=42)$ \\
\hline No Response & $1 \%(n=1)$ \\
\hline \multicolumn{2}{|l|}{ 3. Location } \\
\hline Village & $72 \%(n=124)$ \\
\hline Town & $13 \%(n=22)$ \\
\hline City & $16 \%(n=27)$ \\
\hline No Response & $0 \%(n=0)$ \\
\hline \multicolumn{2}{|l|}{ 4. Occupation } \\
\hline Medical Professional & $13 \%(n=22)$ \\
\hline Other & $71 \%(n=122)$ \\
\hline No Response & $17 \%(n=29)$ \\
\hline \multicolumn{2}{|l|}{ 5. Marital Status } \\
\hline Single & $8 \%(n=13)$ \\
\hline Married & $78 \%(n=135)$ \\
\hline Divorced & $11 \%(n=19)$ \\
\hline Widowed & $3 \%(n=5)$ \\
\hline No Response & $1 \%(n=1)$ \\
\hline
\end{tabular}

the villages of Armavir and Lori Marz in the Northern Armenia, COAF development sites, to a convenience sample of 173 women.

Surveys were collected anonymously and numbered for further analysis of data. Questions and responses were assigned distinctive codes, digitalized, and analyzed using Microsoft Excel. Tables and figures were also created using the same platform.

\section{Results}

\section{Study sample}

The study sample consisted of 173 respondents aged from 15-85 with most of respondents' age ranging between 25-44 (58\%). All respondents had at least a high school diploma or its equivalent. Most of the participants were either married or divorced/ widowed. $13 \%(n=22)$ were medical professionals, predominantly nurses (Table 1 ). Preliminary analysis showed no difference between responses provided by urban vs. rural participants. However, we found an intriguing dynamic between responses provided by medical professionals and general participants. Therefore, all participants were separated in two groups during data analysis, medical professionals and other (general respondents).

\section{Sexually transmitted infections question set}

Survey results show that only $13 \%(n=20)$ of general respondents and $41 \%(n=9)$ of medical professionals correctly identified all the diseases classified as STIs. The most commonly chosen answers to the question asking to identify sexually transmitted infections among general respondents were HIV, syphilis and genital herpes $(67 \%(n=101), 51 \%(n=77)$, $45 \%(n=68))$. Medical professionals identified a larger array of STIs (Figure 1a). In a separate question, $34 \%(n=59)$. of all respondents correctly thought that STIs could be asymptomatic. Genital discharge, itching and burning, and painful urination were the most commonly and correctly selected answers for STI symptoms by both general respondents $(54 \%$ ( $n$ $=81), 48 \%(n=73 \%), 25 \%(n=37)$ respectively) and medical professionals $(73 \%(n=16), 68 \%(n=15)$, $23 \%(n=5)$ respectively) (Figure $1 b)$. The majority of both general respondents $(59 \%(n=89))$ and medical professionals $(68 \%(n=15))$ chose condom use as a primary route of STI prevention. Interestingly, $11 \%$ ( $n$ $=16)$ of general respondents and $18 \%(n=4)$ of medical professionals also chose abstinence as a method of STI prevention (Figure 1c).

\section{Cervical cancer question set}

Based on the survey results, only $27 \%(n=41)$ of general respondents and $32 \%(n=7)$ of medical professionals correctly identified HPV as the cause of cervical cancer. Interestingly, $20 \%(n=30)$ of general respondents and $41 \%(n=9)$ of medical professionals marked genetics as the culprit for cervical cancer (Figure 2a). Non-menstrual vaginal bleeding, pain during sexual intercourse and intense vaginal discharge were correctly marked as symptoms for cervical cancer by general respondents (41\% $(n=62), 24 \%(n=36)$ and $16 \%(n=24)$ respectively) and by medical professionals $(68 \%(n=15), 50 \%$ $(n=11)$ and $32 \%(n=7)$ respectively) (Figure $2 b)$. In a separate question, $53 \%(n=80)$ of general respondents and $73 \%(n=16)$ of medical professionals correctly said that getting a pap smear decreases risk for cervical cancer while only $11 \%(n=17)$ of general respondents and none of the medical professionals chose vaccination as a mean of decreasing risk for cervical cancer (Figure 2c). Regarding vaccination to prevent cervical cancer (the HPV vaccination), $71 \%(n=123)$ of all respondents said they do not know if such a vaccine exists; only $22 \%$ ( $n=$ 38) seemed to know about the vaccine.

\section{Contraceptive choices question set}

Of all respondents, $18 \%(n=31)$ said that they 


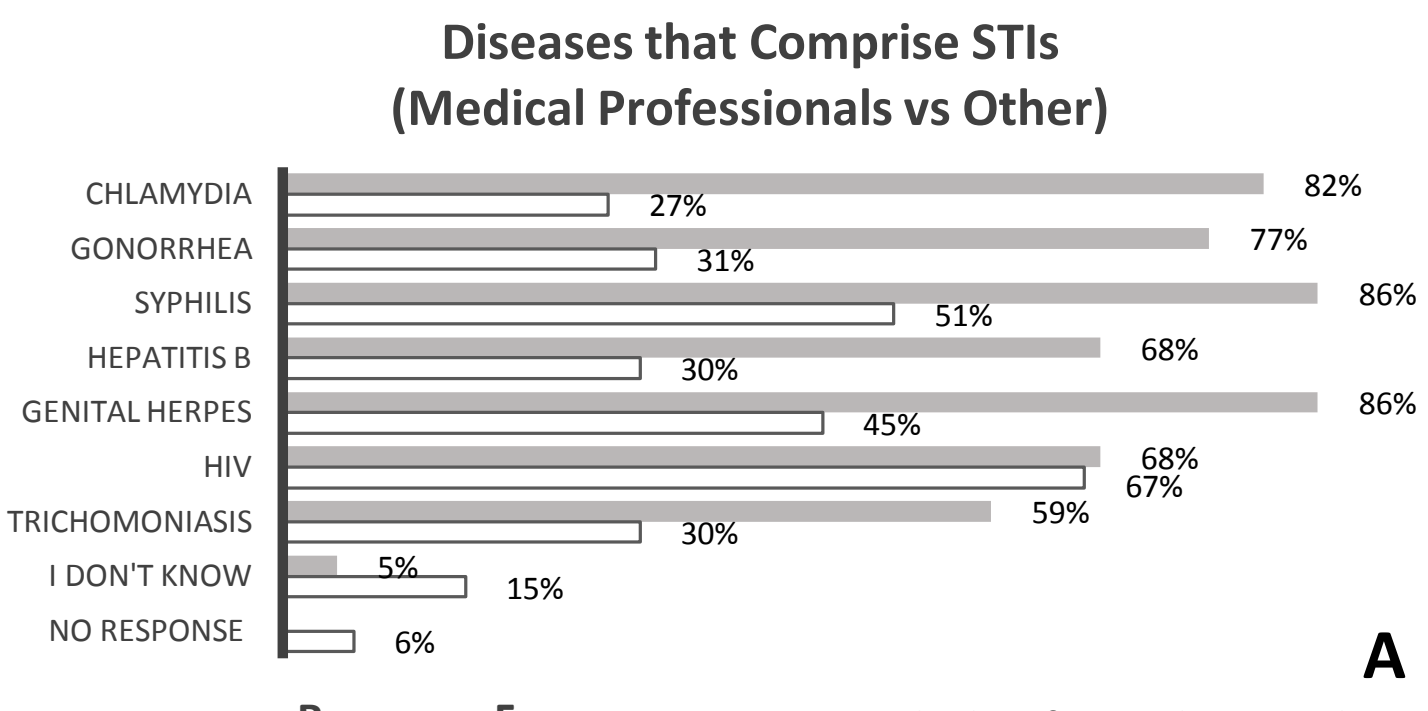

Response Frequency $\quad$ Medical Professional $\quad \square$ Other

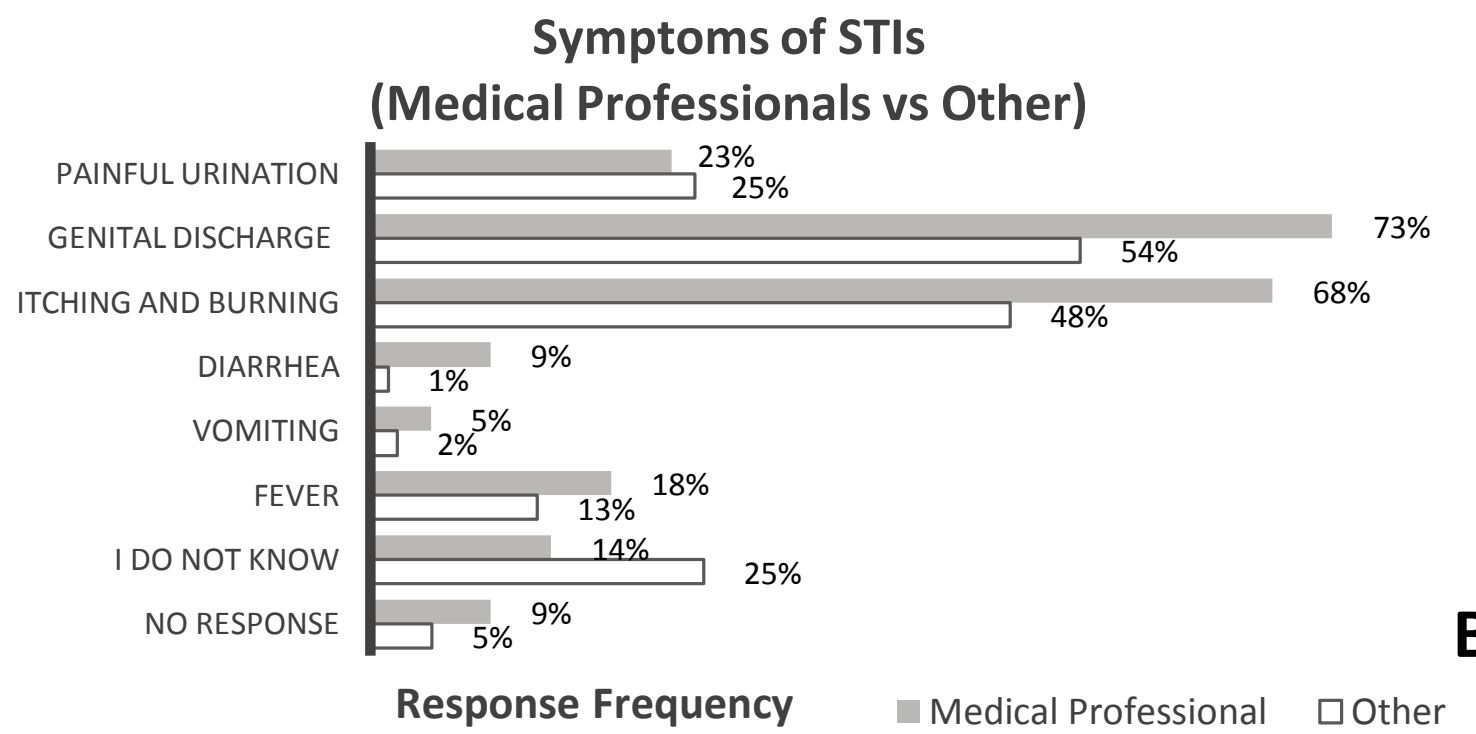

Methods to Prevent STIs

(Medical Professionals vs Other)

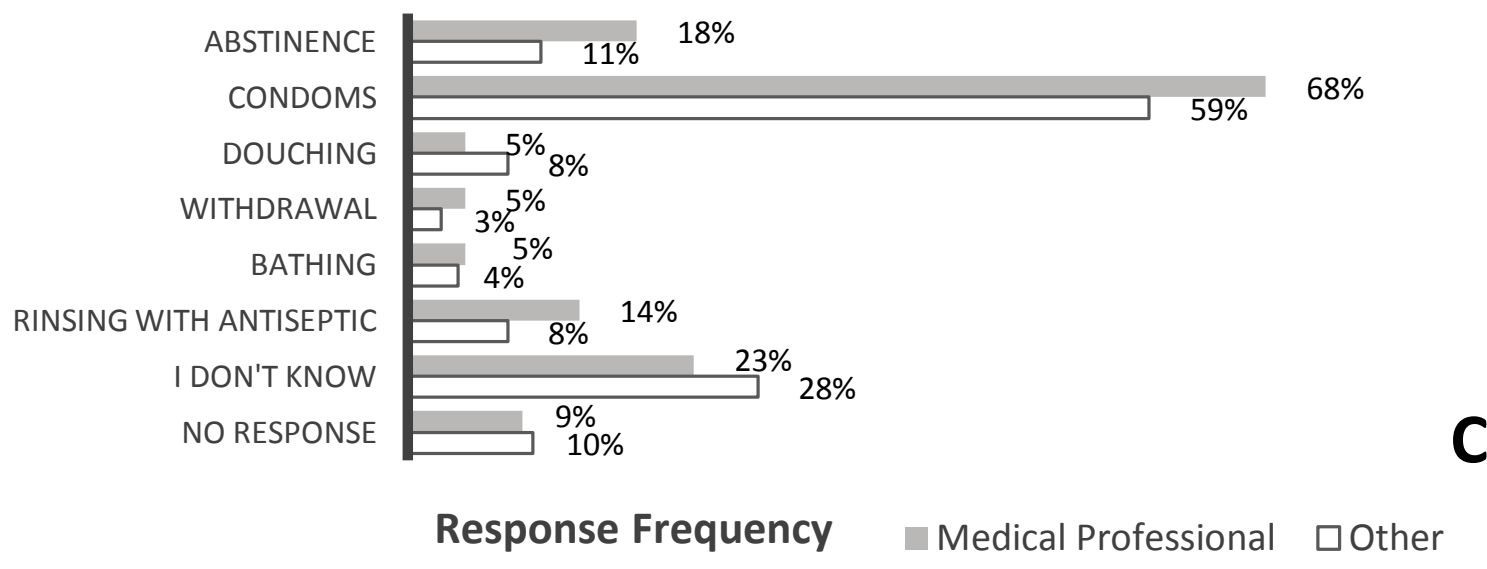

Figure 1: Sexually Transmitted Infections Question Set Analysis. Comparing medical professionals' $(n=22)$ vs. general public's ( $n=151$ ) responses regarding: A) Diseases that comprise STIs; B) Symptoms of STIs; C) Methods of STI Prevention. Abbreviations: HIV: Human Immunodefficiency Virus, PID: Pelvic Inflammatory Disease. 


\section{Cause/s of Cervical Cancer}

(Medical Professionals vs Other)

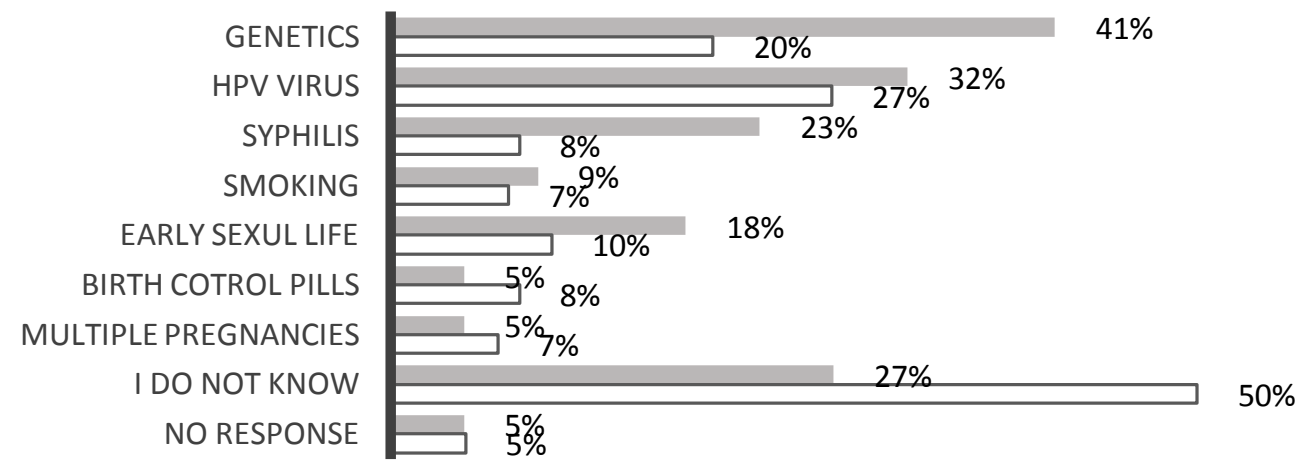

Response Frequency $\square$ Medical Professional $\square$ Other

\section{Symptoms of Cervical Cancer}

(Medical Professionals vs Other)

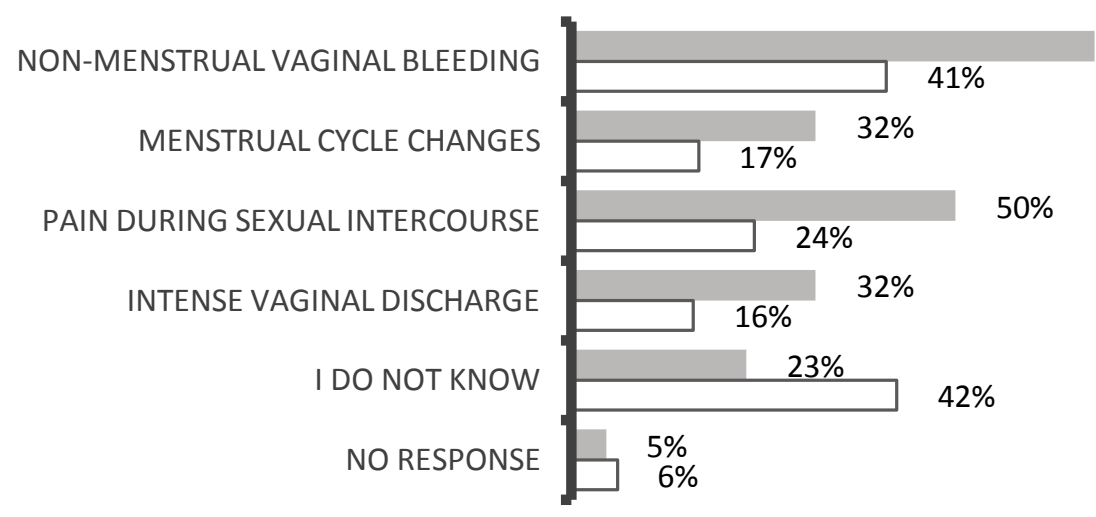

$68 \%$

Response Frequency $\square$ Medical Professional $\square$ Other

\section{Cervical Cancer Risk Reduction \\ (Medical Professional vs Other)}

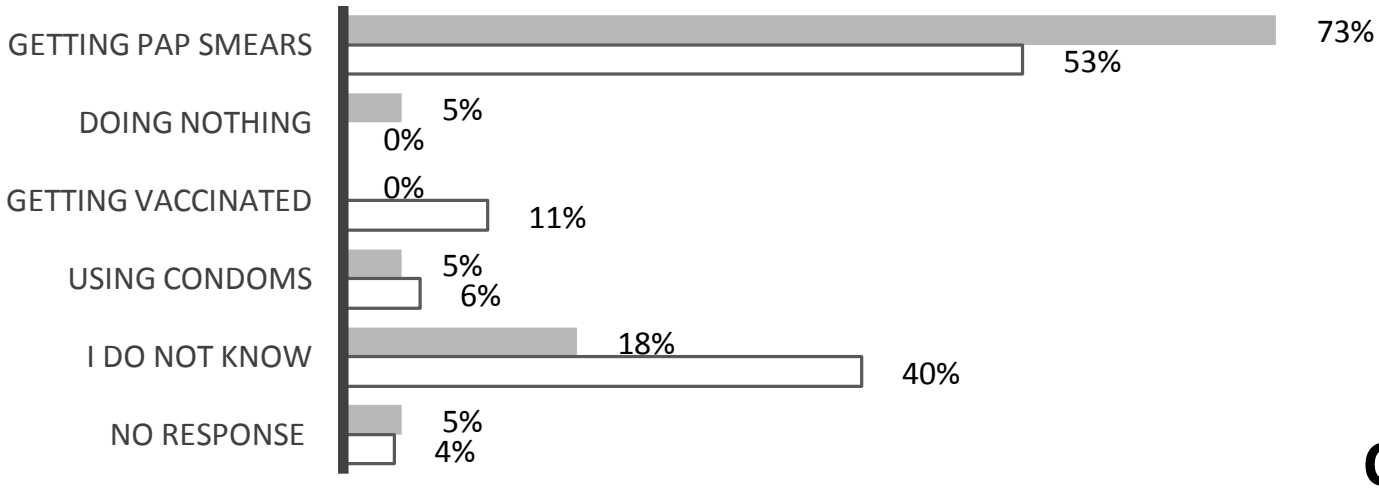

Response Frequency Medical Professional $\square$ Other

Figure 2: Cervical Cancer Question Set Analysis. Comparing medical professionals' $(n=22)$ vs. general public's $(n=151)$ responses regarding: A) Causes of cervical cancer; B) Symptoms of cervical cancer; C) Cervical cancer risk reduction. Abbreviations: HPV: Human Papillomavirus. 


\section{What birth control do you use?}

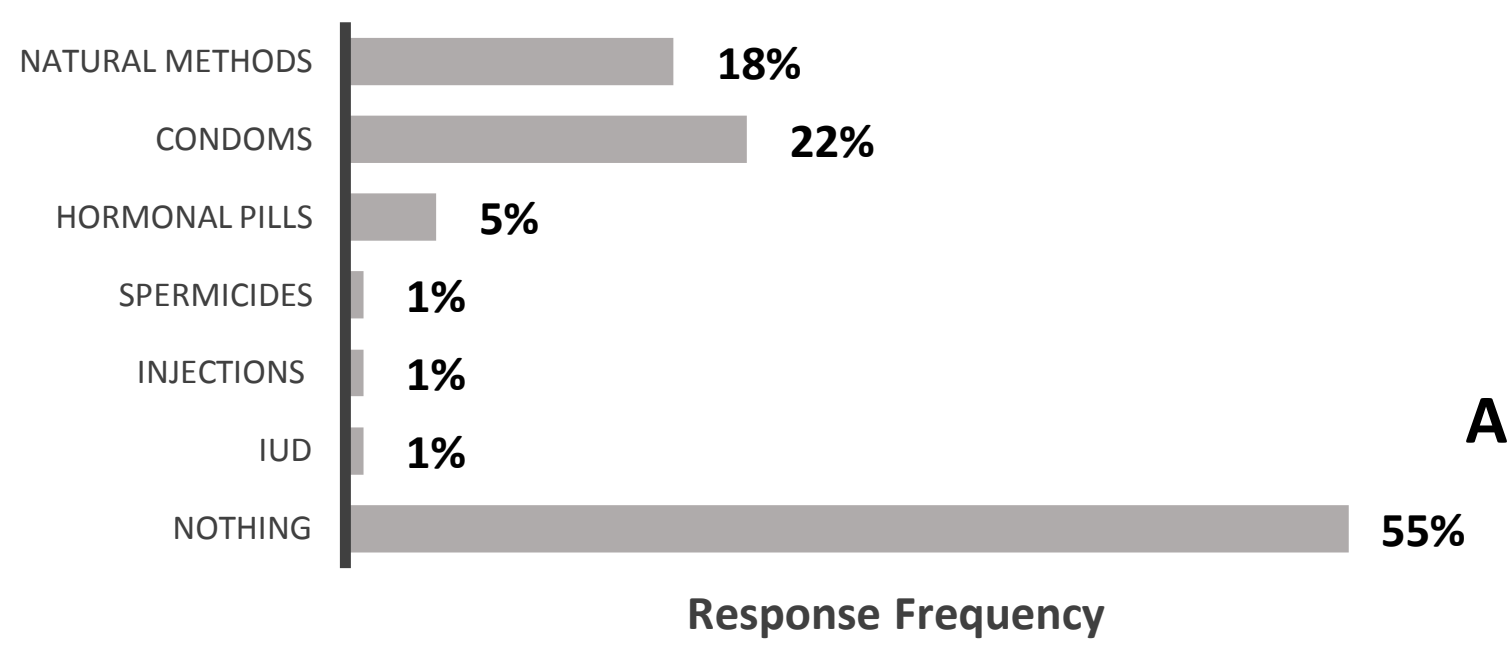

\section{Do you use condoms?}

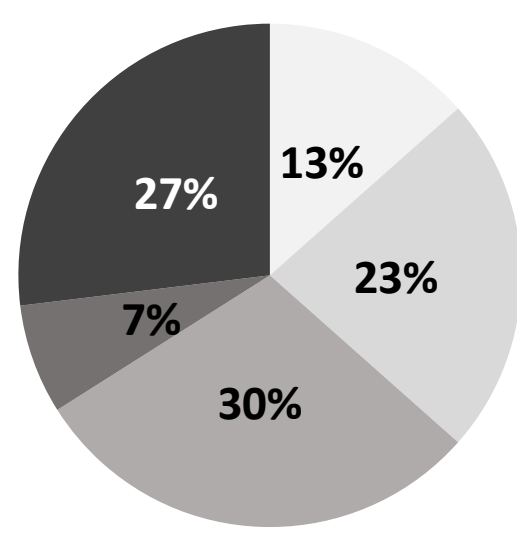

$$
\text { Yes, always }
$$

Yes, sometimes

No, usually not

No, it's up to the man

never used and never will

B

\section{Have you had abortions?}

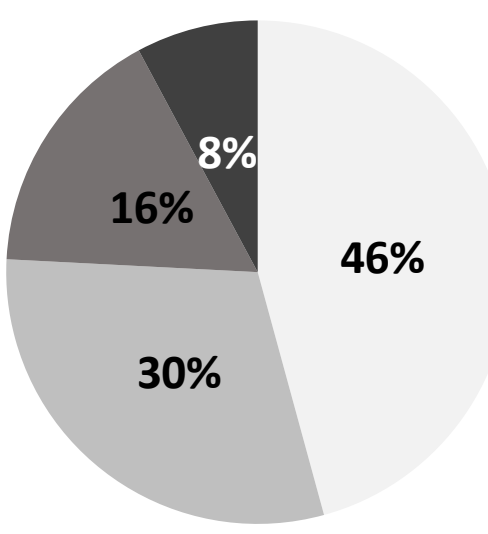

\section{Never}

Yes, once

- 2 - 5 times

- More than 5 times

Figure 3: Contraceptive Choices Question Set Analysis. Comparing medical professionals' $(n=22)$ vs. general public's $(n=151)$ responses regarding: A) Use of birth control; B) Use of condoms. C) Aboortion history. Abbreviations: IUD: Intrauterine Device. 
prefer "natural methods" of birth control, like using a calendar to establish the time of ovulation and to remain abstinent. Only $22 \%(n=38)$ of all respondents reported condom use while $5 \%(n=9)$ said that they use hormonal pills (Figure 3a). In the question concerning condom use specifically, $27 \%(n=47)$ denied any use with $30 \%(n=52)$ also denying habitual use of condoms. Only $13 \%(n=22)$ reported consistent use of condoms while $23 \%(n=40)$ said that they use condoms "sometimes". Interestingly, 7\% ( $n=12)$ of respondents said that they leave the decision of using a condom up to their male partner's discretion (Figure $3 \mathrm{~b})$. Of note, third of respondents $(30 \%(n=52))$ reported having had at least one abortion, 16\% ( $\mathrm{n}=$ 27 ) reported 2 - 5 abortions and $8 \%(n=14)$ said that they had more than 5 abortions (Figure 3c).

\section{Discussion}

We identified a significant deficit of knowledge among survey respondents regarding STIs, cervical cancer and reproductive health even among survey population consisting of high number of rural medical personnel. In that the overwhelming majority of respondents $(84 \%(n=146))$ came from villages and small towns, it is clear that education formally provided through schools or other community organizations concerning reproductive and sexual health is insufficient. Currently, there are no other formal means of learning about these topics. Even more concerning is the poor of level of understanding around reproductive health issues demonstrated by medical professionals in the community. If these people are poorly educated on such topics, it does not bode well for the women in the community who need to depend upon them for information and guidance. Our study also revealed that most respondents $(88 \%(n=152))$ used no mode contraception or relied on "natural methods". Less than a quarter of respondents reported consistent condom use leaving abortion as their primary method of contraception. This is not ideal and can lead to downstream problems.

Our findings are in agreement with the conclusions drawn in the 2015-2016 Armenia Demographic and Health Survey, which indicates that amongst people aged $15-24$ only $20 \%$ of women and $13 \%$ of men have knowledge about HIV prevention [7]. The study acknowledges that between both sexes, the proportion with comprehensive knowledge generally increases with age, educational attainment, and wealth. Yet amid the same age group, $24.9 \%$ of urban Armenian women, and $15.6 \%$ of urban Armenian men had knowledge about HIV prevention. This represents a significant problem for preventing the spread of HIV in Armenia, as Armenia is part of the region with fast growing HIV/AIDS epidemic [5]. Importantly, 5\% of men ages 15-49 reported that they had two or more sexual partners in the last 12 months and just under two-thirds of them reported using a condom during their last sexual intercourse. Statistics such as these indicate that significant measures ought to be taken to prevent the spread of STIs through providing a complete sexual health education course to the public, especially those from rural areas.

Since sexual intercourse is also the primary route of transmission of human papilloma virus, the leading cause of cervical cancer, sexual and reproductive health education also plays a major role in prevention of cervical cancer. Cervical cancer in Armenia is the $5^{\text {th }}$ most frequent cancer among women and the $2^{\text {nd }}$ most frequent cancer among women 15-44 years of age [8]. Our results demonstrate lack of literacy regarding causes, symptoms and modes of prevention of cervical cancer among the majority of rural respondents. Only, a little more than half of the surveyed women knew about the pap smear and most were not aware of the link between pap smear tests and cervical cancer detection. Few were aware of HPV vaccination. This is likely due to the fact that Armenia implemented HPV vaccine only in December of 2017 [9].

Despite the fact that there is no established information on contraceptives at a governmental level in Armenia, most types of contraceptives are available in the country [10]. Misconceptions and lack of knowledge regarding certain contraceptive methods along with the fact that no single type of contraceptive is subsidized in Armenia force low income part of the society to rely on abortion as a primary mode of contraception [11]. Our study revealed that most of the respondents did not use any mode of contraception or relied on "natural methods", using a calendar to follow their menstrual cycle to be able to distinguish the ovulation window and to remain abstinent during that time to prevent pregnancy. Less than a quarter of respondents reported consistent condom use while a fraction of women said that they leave the condom use up to their male partner's discretion demonstrating deeply rooted ancient patriarchal traditions of the country. According to Dolian, et al. lack of contraception use is due to absence of contraceptive education, unavailability or elevated cost of contraceptives, and medical contraindications [12]. Thus, it was not surprising that we also observed that our respondents, primarily village and small-town residents, seem to rely on abortion for contraception, including increased rates of utilization of medical abortion using a medication called Cytotec (Misoprostol) [11]. Abortions have been legal in Armenia since the Soviet Union times and still remain popular despite potential dangers compared to other modes of contraception due to unmet need of family planning [11]. United Nations Economic Commission for Europe Regional Report describes the value of unmet need for family planning to be $10 \%-15 \%$ in Armenia. This issue is especially dire in rural communities where lack of family planning professionals and availability of con- 
traceptives is especially severe [13]. Decreased rates of condom use additionally exposes these women to STIs as is discussed above.

Our study sought to evaluate two specific areas of reproductive health (STIs and cervical cancer) as well as assess contraceptive choices of women. We identified identified poor state of knowledge around STIs and cervical cancer among women in Armenia. Reproductive health is paramount to a healthy nation and public awareness of the diseases causing adverse outcomes on fertility cannot be underestimated. Inadequate sexual health education and cultural taboos prevent women from acquiring information about, STIs, and cervical cancer. Consequently, since women in Armenia are largely ill-informed about reproductive health, obtaining proper medical care and advice becomes a monumental challenge. Undoubtedly, women of lower socioeconomic status and those from rural areas are especially affected by the lacking sexual health curriculum, as they are at a higher risk for contracting STIs, because of the increased likelihood that their potential sexual partners are labor migrants. To address the nominal access to reproductive education, a network of professionals needs to design and develop resources (printed as well as electronic) that will cover variety of topics concerning reproductive and sexual health while also providing expert advice to the community and training school teachers and rural health care professionals. Likewise, sexual education courses should dismantle the cultural taboos associated with sex through facilitating honest discussions about relationships, sex, and pregnancy. Student questions should be taken seriously and if information is unable to be addressed by the instructor, efforts should be made to contact a health professional, so that the student can attain an informed answer. Demystifying reproductive behaviors will increase public awareness about sexual diseases and will safeguard against risks associated with sexual activity.

\section{Acknowledgments}

We would like to extend our sincere gratitude to Nune Dolyanand, Lusine Antonyan, physicians at the Children of Armenia Fund (COAF) and Anush Poghosyan from Women's Resource Center, who helped with administration of the surveys.
There is no funding source for this study. All expenses and time commitment of the authors is voluntary and with an intention to inspire improvement of the demonstrated poor state of reproductive and sexual health literacy in Armenia.

The authors declare that they have no competing interests.

\section{References}

1. Delpech VFH, Lazaurs J, Sönnerborg A, Subata E (2015) HIV programme review in Armenia. World health organization regional office for Europe.

2. (2015) Global AIDS response progress reporting 2015.

3. (2002) Law of reproductive health and rights to reproduction.

4. Kosakyan $L$ (2016) Is there sexual education in Armenia?.

5. Szostak M (2011) Sexual and reproductive health and rights of adolescents in central and eastern europe and balkan countries. ASTRA Youth report.

6. Jessica M Sales, Ralph J Di Clemente (2010) Adolescent STI/HIV prevention programs: What works for teens?. Research facts and findings. A collaboration of Cornell University, University of Rochester, and New York state center for school safety.

7. (2015) Demographic and health survey 2015-2016. Yerevan, Armenia.

8. (2015) Human Papillomavirus and related diseases report. ICO HPV Information Centre.

9. Badalian N (2017) Armenia will start vaccination of girls at the age of 13 from papillomavirus from December 2017. ARM INFO Information Company.

10. Vardanyan S. Reproductive services in Armenia. Country Report, in Women's Rights Center of Armenia.

11. Hamlet Gasoyan, Roza Babayan, Shant Abou Cham, Samvel Mkhitaryan (2016) Public inquiry into enjoyment of sexual and reproductive health rights in Armenia. United Nations Population Fund, Armenia.

12. G Dolian, F Ludicke, N Katchatrian, A Campana, A Morabia (1998) Contraception and induced abortion in Armenia: A critical need for family planning programs in eastern Europe. Am J Public Health 88: 803-805.

13. Guram Matiashvili SM, Tatul Safaryan, Nune Soghomonyan (2008) Availability and affordability of contraceptive commodities in pharmacies and primary healthcare facilities in Armenia. USAID from the American People. 